\title{
Ortega y Wittgenstein: no tan lejos
}

\section{(Ortega and Wittgenstein: Not so far)}

\author{
Antoni DeFEZ
}

Recibido: 19 de abril de 2013

Aceptado: 8 de octubre de 2013

\section{Resumen}

En este artículo se pretende analizar hasta qué punto las filosofías de Ortega y Wittgenstein compartirían un horizonte filosófico común. En este sentido se presentan, aunque con matices distintos, los siguientes elementos comunes: el rechazo del realismo metafísico y el cientismo, el abandono de la concepción sustancialista del sujeto, la irrupción en la discusión filosófica del significado o el sentido como algo que necesita comprensión o aclaración, la urgencia de solucionar el problema de la autenticidad.

Palabras clave: Ortega, Wittgenstein, realismo metafísico, sujeto, significado, autenticidad.

\begin{abstract}
This article aims to analyze to what extent the philosophies of Ortega and Wittgenstein share a common philosophical horizon. In this sense we note, although with different nuances, the following common elements: the rejection of metaphysical realism and scientism, the abandonment of the substantialist conception of the subject, the emergence in philosophical discussion of meaning or sense as something that needs understanding or clarification, the urgency of solving the problem of authenticity.
\end{abstract}

Keywords: Ortega, Wittgenstein, metaphysical realism, subject, meaning, authenticity. 
No hay duda: Ortega y Wittgenstein no sólo crearon filosofías diferentes -tenían estilos, objetivos, intereses y métodos dispares-, sino que fueron también personajes, genios, bien distintos. Sin embargo, esas divergencias no hacen, creo, que sus pensamientos de fondo fuesen radicalmente distantes. Más bien diría que comparten cierto aire de familia: que sus horizontes filosóficos no eran horizontes del todo lejanos. Y no porque pertenezcan a una misma época y generación-Ortega nació en 1883 y Wittgenstein en 1889-, sino porque, por decirlo con una exageración heideggeriana, los dos forman parte de una misma epocalidad del pensamiento occidental: Ortega y Wittgenstein - sobre todo el segundo-, y Heidegger, quien nació también en 1889 y de quien igualmente diremos alguna cosa. Pero concretemos: ¿cuáles fueron esos horizontes cercanos? ¿En qué consiste ese parecido familiar?

Bueno no es fácil presentarlo en cuatro frases, y mucho menos de una forma que sea válida por igual de ambos autores. Con todo, aventurémonos a coger algunos mimbres, que los cestos vendrán después. Pues bien, en primer lugar tenemos la impugnación del tradicional esquema "sujeto-objeto", impugnación que no sólo conllevará la crítica del intelectualismo y el rechazo de la concepción sustancialista del sujeto, sino también el abandono del realismo metafísico y del cientismo como caso particular suyo. Dos: la irrupción en la palestra filosófica del significado o del sentido, realidades que no requieren tanto una explicación como una comprensión o aclaración. Tres: el desinterés por lo epistemológico o la teoría del conocimiento entendida como una respuesta al escéptico o como reconstrucción y fundamentación del conocimiento humano. Por último: la urgencia de la cuestión de la autenticidad -la responsabilidad para con uno mismo, si se quiere.

Salta a la vista que, de estos mimbres, los tres primeros están íntimamente interconectados -el problema de la autenticidad hasta cierto punto come aparte-, de manera que será conveniente presentar la urdimbre que generan: la imagen que nos dan de los seres humanos, de la realidad, del conocimiento, del lenguaje y también, claro está, de las responsabilidades que se exigen a la filosofía. Contra ese transfondo -de hecho, y por decirlo a la wittgensteiniana, una imagen que no tiene donde aplicarse- creo que podremos apreciar mejor las posiciones de Ortega y Wittgenstein, así como sus diferencias y cercanías.

Empecemos por la cuestión del realismo y, en concreto, por el enemigo común: el realismo metafísico. Se trata ésta de una posición dominante en la historia del pensamiento que podemos caracterizar mediante las dos tesis siguientes que expresan claramente una radical distinción entre sujeto y objeto:

(i) que la realidad existe por sí misma con una estructuración ontológica en objetos, propiedades y hechos que es previa e indiferente a nuestro tracto 
epistémico con ella, es decir, objetos, propiedades y hechos que, digámoslo así, se autoidentifican;

(ii) que existe o que podría existir -o que no existe, ni puede existir- un conocimiento de la realidad que sea "el conocimiento" de la realidad, esto es, un único conocimiento que la reproduzca de forma verdadera y plena.

Éste es el esqueleto, el maniquí que luego se viste de maneras diversas: el realismo de sentido común, el esencialismo bien sea filosófico o científico, el fenomenismo, el realismo indirecto, el realismo nouménico, el realismo crítico que postula la verdad como límite asintótico, el idealismo, y también el escepticismo y relativismo radicales que propugnan respectivamente un nada o un todo vale. La diferencia entre toda esta casuística depende, en buena medida, de cómo se interprete (ii). Por ejemplo, si el conocimiento de la realidad en sí misma es o no una posibilidad humana; $\mathrm{y}$, de serlo, si es posible o no en algún momento determinado de la empresa y mediante qué procedimientos... Y es que quien manda aquí es el componente epistémico: de hecho, se propone (i) porque se supone (ii).

Asimismo la prevalencia de (ii) muestra igualmente el estrecho vínculo que hay entre realismo metafísico y la concepción intelectualista de los seres humanos y del conocimiento, y además hace comprensible también por qué la correspondencia sería la interpretación de la verdad más favorecida. Y algo más todavía: por qué el realismo metafísico suele ir acompañado por el realismo semántico, bien bajo la forma del referencialismo o como un conceptualismo. Es fácil de entender: supones que el conocimiento lo es de la realidad en sí misma; que lo es porque se corresponde con ella; que se corresponde con ella porque captura y reproduce su estructuración ontológica; y que la captura y reproduce porque las palabras con que se construye el conocimiento hacen referencia a los segmentos ontológicos en que está estructurada la realidad en sí misma, segmentos que son y son como son por cuenta propia.

Con todos estos supuestos en la mano, cuáles hayan de ser las responsabilidades de la filosofía parecen también dadas: explicar si existe y cómo es la realidad en sí misma, explicar si el conocimiento de la realidad en sí misma es posible y de qué manera o si tiene razón el pirrónico, explicar en qué consiste la verdad entendida como correspondencia, explicar la relación isomórfica lenguaje-pensamientorealidad, etc. En suma: unas expectativas excesivas que nunca se han visto satisfechas. Demasiada responsabilidad.

Pero ¿por qué el filósofo habría de tomárselo de esa manera? ¿Y si no tuviese sentido hablar de la realidad en sí misma y del conocimiento de la realidad en sí misma? ¿Por qué aceptar el esquema sujeto-objeto y, así, la idea de que la realidad se encuentra enfrente del sujeto, y que éste llega a aquella mediante el lenguaje, el pensamiento y el conocimiento intentando descubrir su ser? ¿A qué viene ese deseo 
de decir cómo es la supuesta realidad en sí misma? ¿Qué ganamos con todo ello? De acuerdo, prescindamos del concepto de realidad. Ahora bien, ¿de todo concepto de realidad o sólo del concepto de realidad en sí misma? Si optamos por la primera ruta nos instalaremos en un irrealismo: todo es lenguaje, discurso e interpretación. Eso sería un ficcionalismo. Por el contrario, si apostamos por la segunda vía nos deslizaremos hacia un antirrealismo, un realismo que no es un realismo metafísico, y para el cual la realidad siempre es la realidad humanamente conocida y hablada, no teniendo sentido ir más allá.

Cierto, no tiene sentido ir más allá de nuestra praxis lingüística y epistémica, pero no nos confundamos: la realidad no es lo que decimos y conocemos, sino aquello de lo que hablamos y aquello que conocemos, aunque sólo cabe describirla desde nuestra manera de hablar y conocer. Antropomorfismo, pues. Ahora bien, la realidad es igualmente lo que acaece, y hace bondad o se opone a lo que decimos y pretendemos conocer: lo que se nos resiste o se deja hacer. Así que más antropomorfismo. La realidad es lo que hace verdaderas o falsas nuestras expectativas, y lo que permite que tengamos los conceptos que tenemos y muchas de nuestras certezas indudables -las creencias en que vivimos. Otras creencias básicas y otros conceptos podrían haber sido posibles -los nuestros no son metafísicamente correctos: no tiene sentido hablar aquí de corrección metafísica- y, sin embargo, no todo habría sido posible.

Un concepto, pues, doblemente antropomórfico de realidad, claro está, envuelto de silencio: hemos llegado al límite de lo pensable. Pero eso no es algo, ni tampoco una nada: sólo que la pala se dobla. Nada hay de que hablar, ni nada que pensar más allá de constatar ese residuo que es la presión de los hechos, unos hechos siempre humanamente descritos y cognoscibles. Es el terreno de las metáforas, porque ¿no es una metáfora, una metáfora moral, apelar a la bondad de los hechos? Desde luego, pero es una metáfora que, a diferencia de la metáfora de la correspondencia, nos libera de pseudoconceptos y de responsabilidades exageradas. Y es que lo propio del conocimiento es únicamente que sea virtuoso, que cumpla con su función de orientarnos: ofrecernos más y mejores observaciones y más y mejores coberturas de juicio y predicción. Conocer no es contemplar, ni describir, ni penetrar, ni descubrir la realidad en sí misma -eso también son metáforas: malas metáforas-, ya que nada significa eso de la realidad en sí misma.

Conocer y hablar son actividades creativas e imaginativas de los seres humanos, actividades que se llevan a cabo tanto consciente como inconscientemente. Además son actividades colectivas -sociales- y, en mucha medida, heredadas, es decir, históricas. Se podría decir, por tanto, que generan sentidos - mundos de sentido- dentro de los cuales transcurre la vida humana y llega a ser lo que es nuestra existencia. Y aquí la función de la filosofía ya no será reconstruir y fundamentar, sino aclarar -describir- el sentido mostrando su posibilidad. La claridad, la mirada perspi- 
cua como objetivo. Ahora bien, ¿el sentido o los sentidos? Es más: ¿esos sentidos o ese sentido acaecen meramente como acontecimientos que se nos viene encima, o debemos contemplarlos como resultado de la praxis humana?

Si nos decantamos por lo primero estaremos, creo, con Heidegger y con un resto parmenídeo: el monismo no quietista del ser deviniendo. Por el contrario, si es la praxis humana la que crea los sentidos, como parecen indicar Ortega y Wittgenstein, entonces lo que tendremos es un pluralismo. Y ambas vías llevan a maneras distintas de mirarse lo que queda del sujeto que ya no es otra cosa que existencia: la relativa pasividad de quien se entrega al destino que destina destinando y así, a larga, la irresponsabilidad de quien sólo escucha y apacienta el ser; o el estoicismo de quien hace lo que puede mientras aguanta. O también, el compromiso y la responsabilidad de quien cree encontrar una trascendencia - una revelación-en la jerarquía social e histórica de ese pluralismo de sentidos mediante una razón vital e histórica. Como vemos, hemos llegado al tema de la autenticidad.

Que Ortega rechaza el realismo metafísico y el intelectualismo lo podemos comprobar, por ejemplo, en 1933 en la lección "La verdad como coincidencia del hombre consigo mismo" incluida en Entorno a Galileo (1947), donde son presentados como dos de los más tercos prejuicios de nuestra tradición, y frente a los cuales propone un giro hacia la radicalidad de la existencia humana-describir y entender lo que significa existir-, cosa que reportará una mejor comprensión del sentido y el estatus del conocimiento y de las otras ocupaciones humanas. Esta programática ya era presente en El tema de nuestro tiempo (1923), obra que reclamaba determinar el lugar que en la vida humana corresponde a la razón. De hecho, como vemos en Ideas y creencias (1934) y en Historia como sistema (1935), éste sería precisamente uno de los males de la forma de vida occidental: la desorientación, el desconcierto que produce comprobar que la razón -la razón calculadora propia del conocimiento científico y del racionalismo- no es la piedra angular sobre la que gira la existencia humana.

Y no se trata de aceptar la bancarrota relativista, ni defender un pragmatismo que supedite la verdad a la utilidad o la conveniencia. Como ya se nos decía en 1916 en "Verdad y perspectiva" justamente esa supeditación -que es llamada por Ortega "lo político", pues la política no es sino pensar utilitario- se muestra en la actitud vital de nuestra (su) época: la búsqueda de buenos medios para fines, sin preocuparse de los fines mismos. Desde luego, no se trata de decir que lo útil sea desdeñable, sino evitar tanto el error de hacer de la utilidad el fundamento del conocimiento, como propiciar una existencia humana falsa o inauténtica. Por el contrario, lo que se precisa es un pensar puro, inútil y desinteresado que, partiendo de la desorienta- 
ción radical del vivir humano, ofrezca claridad sobre cuestiones últimas y transcendentes. Una razón que sea razón vital y también razón histórica: una razón que nos revele tanto el sentido de nuestra existencia individual, como el sentido de nuestra existencia histórica.

Ortega achaca a la Modernidad el error de haber pensado que la perspectiva del individuo era falsa, mientras que, en realidad, únicamente desde el punto de vista del individuo puede mirarse el mundo en su verdad -otra cosa es artificio. Y es que el yo del que habla la filosofía desde Descartes es un yo sustancia, abstracto, impersonal y desubicado -pura razón universal-, mientras que Ortega está pensando en otro tipo de sujeto: la realidad radical de la vida humana, la existencia individual situada en un mundo de circunstancias con las que tiene que habérselas. De manera que no se tratará de tomar el yo como fundamento epistemológico, sino como fundamento del sentido, de los mundos que los humanos son capaces de crear. Instanciar perspectivas, se nos dice en las Meditaciones del Quijote (1914), ya que la perspectiva es el ser del mundo.

Ahora bien, entendamos lo que se nos dice aquí. De entrada, Ortega no sólo estaría en contra del concepto de realidad en sí misma y del conocimiento de la realidad en sí misma, sino que tampoco acepta que realidad y conocimiento sean entendidos como totalidades unitarias y coincidentes de puntos de vista individuales: eso sería una abstracción - una ficción-, ya que lo único real son las perspectivas. Ortega no niega la existencia de la realidad, pero la realidad sólo nos asequible como perspectiva: la realidad existe más allá de las perspectivas -las excede-, pero la perspectiva individual es la realidad radical y originaria, desde la cual la realidad se nos hace presente y sólo desde la cual tiene sentido hablar de ella, conocerla y pensarla. Estamos, pues, ante un realismo antirrealista y pluralista -un perspectivismo. No tiene sentido hablar de un mundo único, sino de los mundos creados por la actividad del hombre -Nelson Goodman aplaudiría.

$\mathrm{Y}$ este pluralismo perspectivista afecta al concepto de verdad, que ahora hay que ponerlo en relación con el concepto más básico de la fidelidad del hombre para con su perspectiva. En concreto: Ortega no rechaza la tradicional adequatio, sino que propugna la anterioridad ontológico-existencial de la verdad entendida como coincidencia. Y es que el problema no es que la realidad nos sea accesible sólo a través de la perspectiva individual, sino que cada ser humano, si quiere conocer la realidad, debe ser fiel a su perspectiva y no pretender contemplarla desde otra distinta, ni desde un punto de vista que finja ser la negación de cualquier perspectiva -es decir, el impersonal ojo de dios o el no menos impersonal cientismo. Y ello evitando también el error de considerar la perspectiva propia como si no fuese una perspectiva: la perspectiva es absoluta pero parcial, y sólo a través del carácter social e histórico de la humanidad podemos llegar a la verdad. He aquí porque razón vital ha de ser igualmente razón histórica. 
Con vemos, Ortega no plantea la cuestión de la fidelidad sólo en términos epistemológicos, sino sobre todo en términos existenciales: el hombre posee una misión de verdad consistente en la coincidencia consigo mismo y con su perspectiva. Es fácil de entender: las cosas no tienen por sí mismas un ser, y como no lo tienen no hay más remedio que hacerles uno a partir de la imperiosa necesidad que tenemos de saber a qué atenernos -el ser de las cosas no es algo oculto a la espera de ser descubierto. Las cosas -las circunstancias- son un sistema de facilidades-dificultades: asuntos o importancias más que sustancias. Y el hombre, por ello, se encuentra enajenado, siendo su quehacer ineludible -la seriedad de la vida- salvar a las circunstancias y coincidir consigo mismo. O como reza el dictum, "yo soy yo y mi circunstancia, y si no la salvo a ella no me salvo yo". Y salvar las circunstancias y salvarse a uno mismo no es otra cosa que dotar de sentido - llevar a la plenitud del significado- lo monstrenco de nuestras circunstancias. De heroísmo califica Ortega este quehacer humano.

La verdad vital, pues, posee la máxima radicalidad, ya que la vida humana es la realidad radical: no hay existencia en abstracto, sino que toda vida se da en unas circunstancias determinadas y bajo una perspectiva específica, dentro de las cuales existimos como náufragos. Y el hombre no tiene otra salida que hacer algo para orientarse -incluso cuando cree no hacer nada, Ortega dirá que todavía hace algo: tiempo. Ésta es la forma primaria y originaria del existir: un quehacer que ha adoptado históricamente diversas formas, siendo el conocimiento sofisticado que nosotros, los occidentales de hoy, poseemos -razón calculadora, ciencia, etc.- sólo una concreción histórica entre otras posibles. Y no sólo el conocimiento: también esa técnica actual que oculta su carácter técnico, como se nos dice en Meditación de la técnica (1939).

Ahora bien, dado que el ser humano, según Ortega, carecería de naturaleza, pero no de historia -o mejor: que su naturaleza es de índole histórica-, debemos tener presente que los humanos no viven sólo inmersos en asuntos o importancias, sino también dentro de un determinado repertorio de ideas y creencias, las cuales forman asimismo parte de su circunstancia. Las creencias y las ideas -la tradición-en que nos movernos constituyen, pues, el terreno sobre el que nuestra vida acontece, y nos ponen delante lo que para nosotros es la realidad -el hombre tiene una esencial preexistencia, dice Ortega. En suma: todo ver es ya un mirar en el que el factum de las interpretaciones es inevitable, bien mediante nuestras creencias heredadas, bien mediante las posibles ideas innovadoras que el hombre va construyendo.

En 1914, en Meditaciones del Quijote, de una manera bastante tradicional, Ortega distinguía entre lo dado sensorialmente y los conceptos -órganos del meditar- que estructuran esa realidad viviente, caótica y amorfa de los sentidos, y que además se estructuran entre sí formando tramas de significación o mundos que llevan a su plenitud de significación a las cosas aisladas. Dicho de otra manera: el 
mirar del concepto tiende una red de relaciones, ordena -salva- a las impresiones en cosas y a las cosas en mundos, porque el sentido de una cosa es la forma suprema de su coexistencia con las demás cosas. Por contra, en 1934 en Ideas y creencias Ortega parece desprenderse de lo sensorial y se centra más en la funcionalidad de lo cognitivo otorgando un papel primordial a las creencias, pues en ellas se vive inconscientemente.

Las creencias formarían, ahora, el entramado en el que transcurre la vida -somos las creencias en que estamos-, a diferencia de lo que ocurre con las ideas o los conceptos que son creaciones conscientes y puntuales -fantasmagorías- que generan mundos de sentido, como lo es la ciencia. Aquí, la comparación con el arte no es impertinente: irrealidades, ultraobjetos. Ahora bien, nada hay fijo, pues muchas de nuestras creencias fueron en su momento ideas, aduce Ortega. Ahora bien, ¿en qué creencias está pensando Ortega? Bueno primordialmente en creencias de orden cultural -la fe en la razón o en la ciencia-, aunque en cierto momento llega a insinuar mediante los ejemplos de la calle, la pared o la Tierra creencias tan básicas como la existencia constante e independiente de los objetos físicos.

Dijimos que el hombre tenía una misión verdad y ahora podríamos añadir una misión de claridad racional y de plenitud de vida o autenticidad. Una plenitud que, arrancando de la toma de conciencia de las circunstancias, no puede tener lugar sin ideas y creencias, y sin las ideas y las creencias recibidas de la tradición que no tienen por qué asumidas acríticamente. De hecho, como atestiguarían las épocas de crisis en contra de las épocas en las que los hombres creen saber a qué atenerse -las épocas clásicas-, respecto del conjunto de soluciones que nos ofrece la cultura, siempre cabe la disputa y el cambio a fin de alcanzar por parte del hombre su plenitud.

He aquí, por tanto, un claro anticartesianismo y antiintelectualismo: los humanos viven siempre imbuidos en algún sistema de creencias, y la duda es parasitaria del creer -en la duda también se está, dice Ortega. En efecto: si existir es perplejidad, desorientación y menesterosidad, lo es porque los humanos en ocasiones ya no sienten como propias las soluciones que las creencias establecidas les deparan: viven entonces inauténticamente y sienten que su vida es inauténtica. Por ello, cabe poner la razón al servicio de la vida y perseguir un vivir ensimismado. Y no es de extrañar pues, no sólo la razón -lo mismo podría decirse del conocimiento y la cultura- emerge de la vida y es resultado histórico suyo, sino que además los seres humanos son seres llamados inexorablemente a la acción, una acción que persigue la plenitud de sentido o la autenticidad: sentir como propias las ideas que se tienen y las creencias en que se está. ¿Y no es eso también claridad: tenerlo claro?

Autenticidad y realidad estarían además en íntima interdependencia. Y es que la función de las creencias y las ideas no consiste sólo en crear ser, sino también en ampliar el mundo, aumentar la vida, dilatar la realidad. Pero no se trata de un estar cada vez más cerca de lo que sea la realidad en sí misma - eso nada significa, ya lo 
sabemos-, sino más bien que el mundo, considerado como conjunto de soluciones y problemas -e ideas y creencias-, lejos de ser algo inmóvil, eterno, uno, fijo y acabado, está siempre bajo la posibilidad de ser agrandado. Como ya escribía en 1910 en "Variaciones sobre la circum-stantia" incluido en Meditaciones del Quijote: "La fidelidad consigo mismo no consiste en un decir sino en un hacer... Y la palabra 'yo' que antes sugería algo quieto... comienza a significar algo activo. 'Yo', es decir, un ensayo de aumentar la realidad".

Ahora bien, ¿cómo debemos entender la autenticidad? Como hemos visto, Ortega se limita a dar observaciones, digamos, formales en términos de coincidencia, fidelidad, perspectiva y salvación. Evoca o apela a la autenticidad, pero sin mojarse. Y eso hasta cierto punto sería comprensible: la autenticidad, pese a ser una cuestión insoslayable en un mundo definido por el individualismo y la autocreación personal -el anhelo de ser yo-, no obstante, es un concepto altamente resbaladizo, en tanto que depende de apreciaciones subjetivas o personales. En este sentido no es de extrañar la idea de entender la identidad personal en términos de narratividad y autodeterminación: la identidad personal, como sucede con el mundo, no ha de ser vista como la identidad de algo ya hecho y acabado que sólo necesitaría justificación, sino como proyecto. Quién quiero ser yo, es la pregunta. Un interrogante urgente y, a la vez, racionalmente incontrolable si lo entendemos en clave de autenticidad como en su día mostraron Th. W. Adorno en La jerga de la autenticidad (1967) y E. Tugendhat en Autoconciencia y determinación (1979), pues ¿cómo va a decirnos la filosofía quién debamos ser?

Sin embargo, la filosofía puede aventurarse a ello, si piensa que tiene una misión. No olvidemos, por ejemplo, el parágrafo 74 de Ser y Tiempo (1927) donde se aclara la historicidad y el destino del Dasein en términos de resolución precursora y retorno a la tradición y al destino común de la comunidad, del pueblo -que el Dasein escoja su héroe, escribe Heidegger. Del pueblo alemán, claro está, que como se nos dice en Introducción a la Metafisica (1935) vive atenazado por Rusia y América -el bolchevismo y el liberalismo-, y que ha de repetir el origen de su existencia histórico-espiritual con el fin de transmutarlo en otro comienzo. Eso es lo que pasa con el ser. Y en lo que consistiría la vida auténtica: el histórico existir propio (autentico) del Dasein.

A Heidegger se le entiende mejor en contexto, es decir, imaginándonos qué veían sus alumnos por la ventana mientras él hablaba del ser: el contexto era político. Y algo similar ocurre con Ortega. Si queremos entender cabalmente qué entiende por autenticidad hay que ir a obras como La deshumanización del arte (1925) y La rebelión de las masas (1930), donde describe formas de vivir inauténticas en la fruición estética o, en general, respecto de la vida social. Una inautenticidad inconsciente -se puede vivir inauténticamente y no darse cuenta. Una vida en la que los humanos se sirven de ideas y creencias que no les son propias -por ejem- 
plo, el igualitarismo-, y que no les permiten coincidir con su perspectiva. Por el contrario, el conservador liberal que era Ortega apela a una concepción organicista de la sociedad y de la historia, una organización estructurada espiritualmente donde cada cual ocuparía el lugar que le corresponde - coincidiendo con su circunstancia y perspectiva-, y donde las élites -la jerarquía del espíritu, los mejores- mandasen porque saben mandar. Como Castilla con respecto al proyecto llamado España, según leemos en La España invertebrada (1921).

Y ello con toda la urgencia que la situación exigía, pues aún es posible otro tipo de inautenticidad. En 1933 en "La verdad como coincidencia del hombre consigo mismo", seguramente viendo avatares históricos cercanos, Ortega escribe: “¿Cabe en lo humano substantiva y formalmente la sinrazón como autenticidad o no es más que un síntoma notorio de crisis y de existencia en falso? He aquí una gigantesca interrogación”. Y tal vez la respuesta a esa negra posibilidad sea esa revelación - esa fe en una realidad histórica trascendente- que en 1935 en Historia como sistema Ortega reclama a la razón histórica, la razón que no es mero intelecto sino comprensión de lo pasado y de lo avenir, y que ha de retornar a los humanos orientación y existencia ilusionada. Un nuevo organicismo social, pues, sin él, dice Ortega, no hay ni cultura, ni estado, ni hay -es lo más terrible- realidad en la propia vida personal.

Wittgenstein también estuvo preocupado por la autenticidad -al menos por la autenticidad de su vida-, y por los aires de civilización que le tocó vivir. Como Ortega, fue un fronterizo: un pie en el XIX y el otro en el siglo corto. De todo ello, que durante mucho tiempo no ha sido muy tenido en cuenta en las exposiciones de su pensamiento como una mera filosofía del lenguaje, Wittgenstein dejó pistas bastante evidentes. Y no me refiero sólo a los ya clásicos parágrafos finales del Tractatus Logico-Philosophicus (1921) donde nos habla de ética y mística, sino también a muchas de las observaciones dispersas que escribió y que ocasionalmente van siendo publicadas - por ejemplo, en Cultura y Valor (1977) y Movimientos del pensar (1997). Y también las citas con que encabezó tanto el Tractatus como las Investigaciones filosóficas (1958): la de F. Kürnberger de que todo lo que puede llegarse a saber se puede decir en tres palabras; o aquella otra de J. Nestroy de que el progreso siempre parece más de lo que realmente es.

Sin duda, sorprende que las Investigaciones vengan encabezadas con una reflexión sobre el progreso, ya que nada de su contenido parece corresponder a ese tópico. ¿Cuál era, pues, la intención? Bueno, tal vez, avisarnos que en filosofía el progreso siempre parece más de lo que realmente es. Así, esa cita podría estar haciendo referencia a la filosofía moderna e ilustrada: el fundamentismo epistemológico, 
el dualismo ontológico, el mito de la privacidad, el prejuicio de que la filosofía ha de entrar el camino seguro de la ciencia, el positivismo, etc. Tal vez, pero seguramente algo más. En el Prólogo Wittgenstein habla de "la oscuridad de los tiempos" que le ha tocado vivir, y con ello parece apuntar, más allá de la historia de la filosofía, a hechos como la Segunda Guerra Mundial y la postguerra. Y sobre todo a la forma de vida propia del período histórico de la Modernidad que ha culminado de esa manera. Una forma de vida caracterizada por la idea de progreso que se manifiesta tanto en el cientismo como en el imperio de la técnica, el industrialismo, el ídolo del crecimiento, el constructivismo, el arte por el arte, la innovación por la innovación, la cultura de masas, el igualitarismo, el atomismo social, y el fascismo o el socialismo.

Y el culto al cuerpo, el deporte y la obsesión del fitness. En 1930 escribía: “Ayer estuve un rato sentado en el jardín del Trinity \& alli pensé cómo el buen desarrollo corporal de toda esa gente va unido, curiosamente, a una falta total de espiritu (no me refiero a una falta de entendimiento). Y cómo, por otra parte, una tema de Brahms está lleno de fuerza, gracia \& ímpetu \& sin embargo él tenía barriga. Por el contrario, el espiritu de los de hoy no tiene ningún resorte bajo los pies" (Movimientos del pensar, págs: 12-13).

El pesimista spengleriano Wittgenstein añoraba la Viena del XIX. Como Ortega, una época de alta cultura y organicismo social opuesta a una época de civilización definida no por el hecho de que las ciencias, las artes y, en general, la vida humana progresen o evolucionen -eso sería algo indiscutible e irrelevante-, sino porque lo que conforma e impregna su espíritu -mejor: su falta de espíritu- es la idea de progreso. Como si fuese indiscutible, de la mano de un optimismo metafísico inaceptable, que el futuro -el presente- tenía que ser mejor que el pasado. Un optimismo metafísico que se plasmaría no sólo en la creencia de que la ciencia es la explicación última de la realidad -de la realidad en sí misma-, sino también en la creencia de que todo está en nuestras manos -todo está permitido-, y que si llegase un momento en que las cosas fallasen, siempre seríamos capaces de encontrar una solución científico-técnica. Incluso las utopías sociales de la Modernidad se habrían constituido así, como física social.

Pues bien, ante el chaparrón estoicismo, un individualismo ético -que no egoísmo- para situaciones extremas: vivir emboscado, protegerse, no desear, no dejarse afectar, alzar un muro a las pasiones, y a las gracias y desgracias que depara el destino, lo que acaece. ¿Cómo? No intentando cambiar el mundo -los hechos-, sino sus límites. El mundo del feliz y del infeliz es el mismo -ambos tienen mundos extensionalmente idénticos: los mismos hechos; la diferencia, por el contrario, la marca la vivencia de esos hechos: la aceptación y la imperturbabilidad. Esa es la vida auténtica -la vida del sabio-, la vida de quien ni tan sólo teme morir. Y por aquí andaría el dios que al parecer Wittgenstein a veces buscaba: un dios con quien 
sentirse seguro, a salvo, un dios al lado del cual nada pueda pasarte. No un dios con quien puedas hablar y que te escucha -dios no habla; tampoco un dios que puedas poner a tu favor propiciando. De hecho, no se necesitan creencias ni religión para vivir con una actitud religiosa: sentirse en absoluta dependencia -en manos de un poder irresistible- y aceptar, puede ser suficiente.

La autenticidad wittgensteiniana no es un añadido a su filosofía. Ya se lo dijo a L. von Ficker por carta: que el significado del Tractatus era lo no escrito, un significado ético. Y la ética -la actitud ética- es trascendental: altera los límites del mundo, dotando de sentido insensato (metafísico, ético) a lo verdadero-falso, es decir, a lo único que estrictamente tiene sentido, lo único que se puede decir, creer, conocer o pensar: los hechos. Un sentido insensato que nace y se muestra en la acción, más allá de las condiciones a priori que la lógica extensional, en tanto que esencia del lenguaje, fija a la significación del pensamiento y a la inteligibilidad del mundo. La lógica es doblemente trascendental, sí; pero la trascendentalidad de la ética es lo que importa: de ella depende la solución al problema de la existencia humana, aquello que queda después de que se han resuelto todos los problemas filosóficos y se ha dicho todo lo que se puede decir -la ciencia. Y Wittgenstein parece decantarse por la ataraxia.

Ahora bien, ¿no es eso en el fondo un solipsismo? El solipsismo, como cualquier otra tesis filosófica, no puede decirse: es una insensatez. Y, sin embargo, una insensatez iluminadora -claridad es lo que pretende la filosofía-, pues ¿no es cierto, de alguna manera, que el mundo empezó el día en que nací? El mundo -mi mundo- y la vida son la misma cosa. No puede decirse, pero se muestra, se me muestra. Como el hecho de que el lenguaje -mi lenguaje- sea el único que yo entiendo. Y que mis razones son mis razones, o que mi actitud ética es mi actitud ética. La poética del solipsismo que, obstante, acaba coincidiendo con el realismo: el mundo es lo que acaece y todos pueden llegar a describir y conocer, incluso como hace la filosofía en su formalidad a priori -que el mundo es siempre un mundo de hechos (concatenaciones de objetos) y el lenguaje siempre una estructura de proposiciones (concatenaciones de nombres). Nótese: Wittgenstein nunca habla de $m i$ lógica, pero sí de $m i$ lenguaje y $m i$ mundo.

Y aquí lo inexpresable, lo privado -lo que se muestra- únicamente es la vivencia de la consciencia lingüística del mundo: la vivencia de esa mirada -esa actividad trascendental- que no ves cuando te miras en el espejo, pero que es condición de posibilidad de que te veas. Es la única manera como el sujeto puede jugar un papel en filosofía. Un sujeto trascendental que no es un objeto -no pertenece al mundo-, sino la actividad no empírica que altera los límites del mundo, y que además hace posible el lenguaje. En concreto: que el lenguaje esté vivo y no sea algo inerte, que nos hagamos figuras de los hechos, que los signos proposicionales sean proposiciones. Y es que la proposición -el acto de habla de decir cómo pueden ser 
las cosas- es lo primero. Lo primero son los sentidos -y con ellos la lógica-; lo segundo los hechos, tanto los hechos del mundo que hacen bondad o no a las proposiciones, como los hechos del mundo que son los signos proposicionales.

Con el lenguaje, pues, aparecen y crecen los sentidos -los hechos posibles-, mientras que el mundo son los hechos que acaecen. Bueno, no sólo los hechos que acaecen -eso sería un reductivismo extensionalista-, sino también y sobre todo el acaecimiento de los hechos: el milagro estético -el enigma- de la existencia del mundo. Sólo así se entiende que pueda existir lo ético y lo místico, y que al final se fundan en el sentimiento -la vivencia- del mundo como un todo limitado e inalterable, un todo necesario e inexplicable que sólo cabe aceptar -el destino, mi destino. Milagro estético y ataraxia. Algo de lo que sólo cabe guardar silencio: o mejor una nada que no es posible ni siquiera pensar, porque aquello de lo que no se puede hablar no es nada. O sólo el milagro de la superficie enigmática que es el mundo acaeciendo. No hay nada oculto de lo que no podamos hablar o pensar, y nada sobre qué callar. Es el silencio - la visión perspicua- del sabio, no la habladuría filosófica del ignorante.

Pues bien, para el Wittgenstein del Tractatus, estas son las coordenadas en las que transcurre la existencia humana y las posibilidades de la vida auténtica. Como vemos, hemos necesitado algo más de tres palabras para presentarlo, y eso que apenas hemos entrado en detalles. Pero el cuadro no estaría completo ni siquiera con esos trazos gruesos: falta todavía decir algo sobre el realismo metafísico. Y es que la habladuría filosófica no sólo se produce cuando intentamos hacer ética, o cuando hacemos una lógica que no se basta a sí misma -que no tiene cuidado de sí misma-, deslizándonos hacia el platonismo. No, la encontramos también cuando, otra vez platónicamente, nos comprometemos con el concepto de realidad en sí misma. Como vemos, Wittgenstein era un furibundo antiplatónico: ¿que no es antiplatonismo la ironía antisocrática de decir que no hay nada que saber? Bien, ocupémonos del realismo.

En las entradas 6.341 y 6.342 Wittgenstein introduce el símil de las mallas para ilustrar cómo los sistemas de descripción de la ciencia -por ejemplo, la mecánica newtoniana- describen la realidad. Pues bien, en su opinión, que el mundo se deje describir por una malla determinada no dice nada sobre el mundo, aunque si dice algo que una malla pueda describirlo de manera más simple o más plenamente que otra. Este segundo "dice algo" -Wittgenstein no dice qué- creo, sin embargo, que debiera ser entendido como un "muestra", ya que no sólo sería una insensatez pretender comparar lenguaje y realidad en sí misma, sino que además tal pretensión formaría parte de la ilusión de la visión moderna del mundo, a saber, que las llamadas leyes de la naturaleza -las leyes científicas- son la explicación de los fenómenos de la naturaleza. Y aquí los antiguos veían mejor -con mayor claridad filosófica: la claridad otra vez- al considerar que no todo se puede explicar, sino que es des- 
tino o voluntad de dios: el milagro estético del acaecimiento de los hechos como límite de toda explicación (vid., Tractatus, 6.371 y 6.372).

Y ¿qué se muestra aquí? No que el mundo sea como lo conocemos o como podamos llegar a conocerlo algún día; tampoco que el mundo sea como pueda ser conocido por desde alguna instancia superior, humana o no. El punto de vista que no es ningún punto de vista -aunque lo concibamos desprendido de toda materialidad, esto es, matemáticamente-, no tiene sentido. Ni siquiera lo tendría decir que existen las leyes de la naturaleza o que el mundo está ordenado causalmente: eso se muestra. Y se muestra a través de la bondad que hace el mundo a nuestros sistemas de descripción, que no son únicamente estructuras extensionales de proposiciones, sino estructuras donde algunas proposiciones tienen forma de ley que generan descripciones unitarias y generales del mundo permitiendo hacer predicciones. En otras palabras: los humanos somos seres inductivos a los que interesan las regularidades, y eso se refleja en nuestros lenguajes y sistemas de descripción. Por ello, aunque la inducción dependa del hábito, y sólo exista la necesidad lógica, lo que excluya la ley de la causalidad no podrá describirse (vid., Tractatus, 6.343-6.35, 6.362-6.37 y 6.36). En suma: que el mundo se deje describir de una manera más simple o más plenamente por una mecánica que por otra muestra que el mundo hace bondad a nuestras pretensiones cognoscitivas, y el resto es silencio. Y recordemos que ese mundo que hace bondad, $\mathrm{u}$ opone resistencia, siempre es un mundo humanamente hablado: sólo la enigmática superficie del mundo hablado, es decir, el darse los hechos que nos imaginamos - pensamos- con las proposiciones.

El Tractatus es una obra llena de tensiones que, además, cabe leerla en muchos aspectos en relación a la filosofía posterior de Wittgenstein. Por ejemplo, esta última observación sobre el carácter inductivo y causal de los seres humanos ¿cómo casa con el sujeto trascendental? Y ¿cómo articular el sujeto trascendental con la persona que cada uno es o llega a ser? Bueno, no nos perdamos por esas sendas, y entremos directamente en el nuevo escenario que abren las Investigaciones y cierra el Sobre la certeza (1969). Por cierto, qué diferencia de actitud entre escribir un tratado que se jacta de haber resuelto todos los problemas y escribir un álbum de anotaciones - unas investigaciones- que únicamente pretende dar claridad y orientar en los laberintos del lenguaje... Y empecemos por el sujeto: "quiero considerar -escribe Wittgenstein el 5 de abril de 1951-al hombre como un animal; como un ser primitivo a quien le atribuimos instinto, pero no raciocinio. Como una criatura en estado primitivo. Y debemos conformarnos con una lógica que sea suficiente para un modo primitivo de comunicación. El lenguaje no ha surgido de un razonamiento" (Sobre la certeza, \# 475).

Menudo cambio. El sujeto en la filosofía madura de Wittgenstein ya no es el sujeto trascendental; tampoco un alma encerrada en un cuerpo, ni una mente encarnada; ni siquiera un cerebro en una cáscara ósea, o un mecanismo que se relaciona 
con el entorno mediante estímulos y respuestas. No, los humanos son seres naturales expresivos, creativos, espontáneos, intencionales, simbólicos y rituales que han creado lenguajes $-\mathrm{o}$, mejor, actividades lingüísticas-, realidades intencionales, mundos de sentido que van transmitiendo y enriqueciendo de generación en generación. Y lo hacen por el entrenamiento de sus comunes maneras de actuar y reaccionar, no mecánicamente o intelectualmente. Aquí que Wittgenstein hable de juegos -juegos de lenguaje- no puede ser casualidad: la acción humana crea y recrea constantemente el lenguaje.

Así las cosas, los humanos son seres situados, ubicados que pertenecen a grupos, comunidades, paisajes, tradiciones, etc., aunque ha llegado a estar a su alcance la capacidad de distanciarse de sus ubicaciones y pertenencias primeras, y abrazar así horizontes de sentido más amplios. Distanciarse sí, pero no desubicarse. Wittgenstein no es un cosmopolita o un universalista ético: no es que no acepte el llamado espacio de razones, pero lejos de todo optimismo metafísico considera que la situación humana, en el fondo, es y será conflicto, un conflicto en el que, cuando se acaban la razones, sólo queda la persuasión o el combate. Que no nos extrañe: lo que vale para el seguimiento de reglas -que las justificaciones siempre llegan a un final, y el final es la acción espontánea enriquecida por el entrenamiento-, tiene consecuencias para los conflictos entre normas, morales o no: cuando acaban las justificaciones cada uno hace valer las razones propias (vid., Sobre la certeza, \#262 y \#612). Pero precisemos más.

Los humanos son esos homínidos que a partir de su evolución natural -la hominización- han ido humanizándose a lo largo su evolución social, cultural y tecnológica. Y no lo habrían hecho recubriendo sus conductas naturales iniciales con lo cultural: la cultura no es un barniz de la naturaleza, ni un vestido que la recubra. No, naturaleza y cultura se relacionan, por lo menos en sus estratos más profundos -sus capas geológicas más básicas- de manera muy distinta: el lenguaje, la cultura, los universos de sentido han crecido a partir de nuestras conductas naturales, y lo han hecho de tal manera que, en ocasiones, no resulta posible separar unas de otras. Por ejemplo, el lenguaje de lo mental y, paradigmáticamente, el de las sensaciones ha crecido imbricándose con nuestras conductas naturales expresivas; y a veces, substituyéndolas, ampliándolas, o haciéndolas más complejas y sofisticadas.

Ahora bien, Wittgenstein no estaba interesado en hacer historia natural: la filosofía debía ser exclusivamente análisis descriptivo de los usos reales del lenguaje y no sólo del lenguaje en su función descriptiva, que era el prejuicio del Tractatus. Y ello con el objeto de hacer aflorar la gramática profunda de los usos -la lógica es ahora sólo un lenguaje entre otros-y disolver, así, los pseudoproblemas típicos de la filosofía tradicional -la habladuría filosófica. Nada de teorías, ni explicaciones. Con todo, alguna apelación al proceso de formación de nuestros conceptos y creencias básicas parece inevitable: hay que neutralizar la idea de que esos conceptos y 
creencias son los metafísicamente correctos, o que se deriven de la llamada realidad en sí misma. Y es que no eran los únicos posibles, aunque no todo era posible. Más en concreto: los hechos generales del mundo, incluyendo los de la naturaleza humana, habrían determinado y al mismo tiempo infradeterminado la aparición de los conceptos y creencias básicas que, de hecho, tenemos. Y quien no lo vea claro que imagine el efecto que tendrían hechos radicalmente distintos (vid., Investigaciones filosóficas, II, xii).

Dicho de otra manera: hemos llegado a hablar contingentemente como hablamos, o a ser lo que somos. Y el resultado ni era necesario ni tampoco es garantía de nada: los humanos somos unos artistas, sí; pero por eso mismo somos capaces de usar los beneficios de la humanización no para neutralizar la crueldad, sino para hacerla más banal y radical. O puede suceder que nuestra humanización nos lleve a una forma de vida dominada por la idea de progreso, una época de civilización. Otra vez estamos en el problema de la autenticidad, y aunque ahora Wittgenstein no diga mucho al respecto, la propuesta del Tractatus todavía podría ser más o menos válida. Los humanos son animales que se buscan a sí mismos en medio de las circunstancias, las tradiciones y las formas de vida sociales que les ha tocado vivir. Y dado que esas tradiciones y formas de vida pueden ser diversas, en caso de conflicto, como decíamos antes, cada cual combatirá por lo suyo cuando se acaben las razones. Ahora bien, ¿es eso la ataraxia, podría preguntar alguien? Desde luego que no. Y es que la ataraxia era sólo un ideal, como también lo era silencio o el poder dejar de pensar. De hecho, ¿no se fue Wittgenstein voluntario al frente en 1914? Y ¿no se nacionalizó británico a raíz de la Anschluss y trabajó de incógnito en el hospital de Londres?

Pero volvamos al problema del realismo, y hagamos un ejercicio que, aunque Wittgenstein no hace y probablemente hubiera desaprobado pues saca a la palabra "realidad" de sus usos cotidianos, creo que aclara en mucho sus observaciones sobre los usos de las palabras. ¿Qué sentido tiene preguntarse por la realidad en sí misma? Por ejemplo, ¿qué ganamos preguntándonos si existen en la realidad en sí misma árboles o dolores? No tiene sentido: la realidad siempre es la realidad humanamente hablada y conocida. $\mathrm{Y}$, así, la única cosa con sentido que cabría afirmar es que sólo tiene sentido decir que los árboles y los dolores existen a partir de nuestras maneras de hablar. Y no sólo que existen, sino también por qué existen de manera tan diferente: porque hablamos de diferente manera de los árboles y de los dolores, porque son usos lingüísticos con gramáticas -reglas- diferentes. En otras palabras: no tiene sentido afirmar que existe lo físico y lo mental, a no ser que con eso queramos decir únicamente que sólo tiene sentido decir que existe lo físico y lo mental a partir de las maneras como hablamos.

¿Y significa eso que los dolores o los árboles son realidades lingüísticas o maneras de comportarnos en nuestras actividades? En absoluto: los dolores duelen 
y los árboles dan sombra: los dolores y los árboles es de lo que hablamos. Pero no hablamos de ellos por que estén allí en un sentido metafísico a la espera de ser nombrados y etiquetados con nuestras palabras. Hemos dicho que sólo tenía sentido decir que existen a partir de nuestras maneras de hablar, pero eso no sería lo único. Mejor deberíamos haber afirmado que sólo tiene sentido decir que existen a partir de nuestras maneras de hablar y de nuestras maneras de reaccionar y actuar, donde maneras de hablar y maneras de reaccionar y actuar forman un todo inseparable.

Pero no vayamos tan rápido: los árboles y los dolores tampoco están allí, en un sentido metafísico, a la espera de ser detectados provocando nuestras reacciones cuando interactuamos con ellos. Más bien son nuestras reacciones -nuestras maneras comunes de reaccionar- las que los destacan, los aíslan, los recortan: así interactuamos con ellos. Y es que nuestras reacciones no serian meras respuestas a estímulos, sino acciones o, si se quiere, acciones quasi-simbólicas que forman entre sí un proto-mundo - un horizonte de significaciones entrelazadas e interdependienteshaciendo importante y definido lo que por sí mismo no sería importante ni nada definido -en realidad, tampoco tendría sentido eso último: "lo que por sí mismo no sería importante ni nada definido". Por eso sólo tiene sentido decir que los árboles y los dolores existen -y aquí el antecedente tal vez sea el Ensayo sobre el origen del lenguaje (1772) de J.G. Herder- a partir de nuestra manera común de reaccionar y actuar, es decir, a partir de nuestra forma de vida en sentido prelingüístico o natural.

Ahora bien, como nuestras reacciones están imbricadas con el lenguaje, sólo tiene sentido decir que los árboles y los dolores existen a partir del todo inseparable que forman nuestras maneras de actuar y hablar, es decir, nuestra forma de vida. He aquí por qué el mundo es siempre un mundo hablado, y por qué carecen de sentido tanto la idea de la realidad en sí misma, como el supuesto de un punto de vista que no es ningún punto de vista -las tesis (i) y (ii) del realismo metafísico. El mundo siempre es un mundo hablado, y el límite de la reflexión filosófica -el lugar donde la pala se dobla- ese "así y así actúan y hablan los seres humanos": el antropomorfismo insuperable. Y he aquí también por qué las definiciones ostensivas no podrían ni comenzar, pues la realidad no esta segmentada por sí misma a la espera de ser bautizada lingüísticamente, sino que es la praxis lingüística junto con nuestras reacciones y acciones naturales aquello que la va segmentando y haciendo significativa. Igualmente he aquí la razón por la que no ha lugar tampoco al referencialismo semántico, ni siquiera en las reconstrucciones causales de la referencia.

Se dice a veces que los humanos tienen mundo, mientras que los animales no. Ésta, sin embargo, sería una afirmación bastante reduccionista, pues los animales también habitan en un mundo -tienen una forma de vida-, aunque no sea un mundo hablado. Los animales tienen también un horizonte de significaciones no lingüísticamente articulado, una forma de vida prelingüística. Y entre sus mundos y el nuestro habría transiciones y transacciones: depende de qué animales consideremos. Por 
ejemplo, los perros pueden saber que su amo acaba de llegar a casa, aunque no pueden saber que vendrá pasado mañana; y son quasi-fetichistas cuando en ausencia de su amo duermen con una de sus zapatillas, aunque no puedan saber que esa zapatilla fue un regalo de cumpleaños. A su vez, si los leones hablasen no los entenderíamos o, al menos, no los entenderíamos demasiado. ¿Y qué pasa con los animales muy alejados de nosotros en la escala evolutiva? Su forma de vida es tan distante a la nuestra que no parece posible ninguna comunicación.

Llegados aquí, vale la pena que comparemos la posición wittgensteniana con lo que Ortega dice hacia el final del apartado 2 del segundo capítulo de Ideas y creencias. Por un lado, afirma Ortega, la realidad auténtica y primaria es un enigma y que por sí misma carece de figura: por eso mismo no merece ser llamada "mundo". Por otro lado, que el mundo o, mejor, los mundos aparecen con los seres humanos y, más en concreto, con la imaginación, siendo aceptados cuando se ajustan a esa auténtica y primaria realidad. Por último, que eso precisamente es lo que no pueden hacer los animales, pues carecen de imaginación: viven siempre atentos, fuera de sí mismos, atrapados siempre en esa red de facilidades y dificultades que sería la realidad primera y auténtica. Los animales carecen de intimidad: no pueden vivir ensimismados.

¿Dónde estaría la diferencia con Wittgenstein? De entrada, no en la primera idea que apunta antiparmenídeamente a una especie de mix del to ápeiron de Anaximandro y el panta rei heracliteano: lo indeterminado acaeciendo constantemente. A su vez, respecto de la segunda idea, si entendemos por imaginación creatividad lingüística, tampoco parece que hubiera diferencias importantes. Por contra, es en la tercera idea donde podemos empezar a ver las discrepancias. Ortega no piensa que los animales tengan una forma de vida o un horizonte de significaciones, aunque sea de manera prelingüística: viven siempre atrapados en esa red de facilidades y dificultades que sería la realidad primera y auténtica. Pero ¿cómo? ¿No hemos quedado que esa realidad no tiene figura, ni determinaciones? ¿Qué sería entonces esa red de dificultades y facilidades? ¿No son eso determinaciones?

Creo, que el problema de Ortega, a parte de cierta imprecisión, proviene de su idea de que los humanos, a diferencia de los animales, carecen de naturaleza o que su naturaleza es histórica, idea que Wittgenstein no compartiría. Para Wittgenstein, ya lo hemos visto, los humanos son seres naturales con historia: tienen historia, pero también naturaleza como los otros animales. Y aquí la naturaleza debe ser entendida como forma de vida natural, es decir, en términos de acción espontánea, intencional, simbólica, etc. Pues bien, precisamente tanto en los humanos como en los animales no humanos sería esa acción la que hace que la realidad sea una red de facilidades y dificultades - un mundo o horizonte de significaciones prelingüísticasy, además, en el caso humano un mundo hablado. De manera que, bien pensado, la idea de una realidad primera y auténtica -el enigma sin figura-, no pasaría de ser una mera metáfora conceptual para indicar que hemos llegado al límite de lo pen- 
sable, al lugar donde debemos callarnos, porque ¿pensamos en algo cuando decimos que pensamos en el acontecer de lo indeterminado? ¿Para qué invocar una realidad auténtica y primera? ¿No nos confunde?

Olvidémonos, de una vez por todas, del realismo metafísico.

Y terminemos ya, volviendo otra vez al solipsismo, un solipsismo razonable. No deja ser curioso el interés que el Wittgenstein de las Investigaciones siente por el solipsismo y la privacidad. Aunque nos los presenta en su versión epistemológica como posiciones a desenmascarar y disolver, ¿no serían una tentación, un tormento filosófico propio? ¿Era también de eso de lo que quería poder dejar de pensar cuando quisiera? No olvidemos que, en su opinión, los pseudoproblemas filosóficos no eran meros errores lingüísticos -digamos, errores técnicos en el uso del lenguaje-, sino visiones que por su profundidad nos hechizan y subyugan. ¿Y de dónde le vendrían esos calambres a Wittgenstein? ¿Qué pretendía refrenar o resituar? Pues bien, no parece descabellado, incluso en la medida en que nos concibamos como animales socializados y doblados de historia, afirmar que quedará siempre el residuo de la intimidad de las vivencias.

Desde luego que no son posibles los lenguajes privados, ni hay conocimiento privado, aunque eso no impida que exista el lenguaje y el conocimiento de lo privado: lo íntimo que no es incomunicable ni incognoscible por los otros. Podemos hablar de lo nuestro: penas, sensaciones, sufrimientos, recuerdos o razones, etc. Ahora bien, no por ello, los otros viven lo que cada uno vive, de manera que el mundo continuaría siendo, de una manera relevante pero inexpresable, mi mundo, pues mi vida y mi mundo son en cierto sentido la misma cosa. ¿Cómo interpretar si no el encargo que Wittgenstein dio al Dr. Bevan, aquello de "Dígales que mi vida ha sido maravillosa"? Por cierto, ¿no sería posible adscribir también un solipsismo de este tipo de Ortega? Perspectiva, salvación, fidelidad, coincidencia, circunstancias ¿no son categorías irreductibles de la existencia individual, de mi existencia, de la existencia de cada cual?

Y déjenme que cierre con un aforismo de G.C. Lichtenberg, ese autor tan wittgensteiniano del siglo XVIII, donde se aúnan antirrealismo, antropomorfismo y solipsismo razonable: "Conocer objetos externos es una contradicción. El hombre no puede salir de sí mismo. Cuando pensamos que vemos objetos sólo nos vemos a nosotros. En realidad, no podemos conocer otra cosa en el mundo que lo que somos y los cambios que nos ocurren. Del mismo modo, nos es imposible sentir "por otros", como se suele decir. Sólo sentimos por nosotros mismos".

\section{Referencias biblográficas}

Adorno, TH. W. (1971): La ideología como lenguaje. La jerga de la autenticidad (1967), Madrid, Taurus. 
LichtenBeRG, G. CH. (1989): Aforismos (1902-1908), México, F.C.E.

HeIDEgGer, M. (2003): Ser y tiempo (1927), Madrid, Trotta.

HeIdegGer, M. (1980): Introducción a la Metafísica (1935), Buenos Aires, Editorial Nova.

HERDER, J. G. (1982): Ensayo sobre el origen del lenguaje (1772) en Obra Selecta, Madrid, Alfaguara.

Ortega y Gasset, J. (1981): Meditaciones del Quijote (1914), Madrid, Alianza Editorial.

Ortega y Gasset, J. (1975): "Verdad y perspectiva", en El Espectador Vol. I (1916), Madrid, El Arquero.

Ortega y GASSET, J. (1964): España invertebrada (1921), Madrid, Espasa Calpe.

ORTEGA Y GASSET, J. (1976): El tema de nuestro tiempo (1923), Madrid, El Arquero. ORTEGA y GASSET, J. (1987): La deshumanización del arte (1925), Madrid, Espasa Calpe.

Ortega y GASSET, J. (1972): La rebelión de las masas (1930), Madrid, Espasa Calpe.

ORTEGA Y GASSET, J. (1976): Ideas y creencias (1934), Madrid, Espasa Calpe.

ORTEGa y Gasset, J. (1971): Historia como sistema (1935), Madrid, Espasa Calpe.

Ortega y Gasset, J. (2004): Meditación de la técnica (1939), Madrid, Alianza Editorial.

ORTEGA Y GASSET, J. (1982): "La verdad como coincidencia del hombre consigo mismo" en En torno a Galileo (1947), Madrid, Alianza Editorial.

Ortega y Gasset, J. (1979): La idea de principio en Leibniz (1958), Madrid, Alianza Editorial.

Tugendhat, E. (1993): Autoconciencia y determinación (1979), México, F.C.E.

Wittgenstein, L. (1987): Tractatus Logico-Philosophicus (1921), Madrid. Alianza Editorial.

WitTGEnSteIn, L. (1985): Investigaciones filosóficas (1958), Barcelona, Editorial Crítica.

Wittgenstein, L. (1987): Sobre la certeza (1969), Barcelona, Gedisa.

Wittegenstein, L. (1995): Aforismos Cultura y valor (1980), Madrid. Espasa Calpe.

Wittgenstein, L. (2000): Movimientos del pensar (1997), Valencia, Pre-Textos.

Antoni Defez

Universitat de Girona

antoni.defez@udg.edu 